\title{
Sua queda é sua dignidade: Eric Weil e Agostinho sobre a "felix culpa"
}

\author{
His fall is his dignity: Eric Weil and Augustine on "felix culpa"
}

Marcelo Perine*

\begin{abstract}
Resumo
O artigo propõe uma aproximação entre a concepção agostiniana do pecado original e a concepção weiliana da atitude da fé na categoria Deus da Lógica da filosofia. Na tradição latina, Agostinho, a quem se atribui equivocadamente a fórmula "felix culpa", situa-se na origem de uma concepção do pecado original que será determinante na concepção de ser humano da antropologia e da moral cristãs. Na Lógica da filosofia de Eric Weil (1904-1977), na exposição da atitude da fé a que corresponde a categoria filosófica Deus, a expressão "sua queda é sua dignidade" parece fazer eco à fórmula supostamente agostiniana. A presente reflexão parte da tese de que a leitura weiliana de Santo Agostinho subjaz à formulação da categoria Deus da Lógica da filosofia, o que permitiu a Weil formular adequadamente a atitude do crente. $O$ artigo sustenta que as linhas fundamentais da concepção de ser humano subjacente à atitude da fé na Lógica weiliana concordam com a concepção antropológica agostiniana decorrente da sua teologia do pecado das origens. Finalmente, o texto sugere que a concepção antropológica agostiniana está presente em filigrana na concepção weiliana do ser humano como finito e livre, claramente de inspiração kantiana.
\end{abstract}

Palavras-chave: Pecado original; fé; Deus; finitude; liberdade.

\begin{abstract}
This paper proposes an approximation between the Augustinian conception of original sin and the Weilian conception of the attitude of faith in the category of God of his Logic of philosophy. In the Latin tradition, Augustine, who is mistakenly attributed the formula "felix culpa", is at the origin of a conception of original sin that will be determinant in the conception of human being of Christian anthropology and morality. In Eric Weil's (1904-1977) Logic of Philosophy, in the exposition of the attitude of faith that corresponds to the philosophical category of God, the expression "his fall is his dignity" seems to echo the supposedly Augustinian formula. The present reflection starts from the thesis that the Weilian reading of Saint Augustine underlies the formulation of the category of God of the Logic of philosophy, which means that Augustine provided Weil a adequately formulation of the attitude of the believer. The article maintains that the fundamental lines of the conception of human being underlying the attitude of faith in the Weilian Logic agree with the Augustinian anthropological conception deriving from its theology of the original sin. Finally, the text suggests that the Augustinian anthropological conception underlines also the Weilian conception of the human being as finite and free, clearly inspired by Kant.
\end{abstract}

Keywords: Original sin; faith; God; finitude; freedom.

Artigo submetido em 26 de junho de 2019 e aprovado em 13 de agosto de 2019.

* Doutor em Filosofia pela Pontifícia Universidade Gregoriana. Professor da PUC-SP. País de origem: Brasil. E-mail: mperine@pucsp.br 


\section{Introdução}

O presente texto foi motivado pela leitura de um brilhante artigo de Luís Manuel Bernardo, um dos mais renomados intérpretes da obra de Eric Weil1, intitulado "Presença de Santo Agostinho na Logique de la philosophie de Eric Weil” (BERNARDO, 2003a). Convencido da verdade da afirmação platônica no final do Fedro (279 C), de que "entre amigos tudo é comum", vou me servir da reflexão do amigo weiliano, como de um fio de Ariadne, primeiramente, para que a ousadia de juntar dois autores tão díspares não acabe produzindo uma espécie de monstruoso Minotauro, em seguida, para me proteger dos riscos de me mover nos labirintos de duas grandes obras da nossa tradição filosófica.

Para começar, duas observações sobre o título deste artigo. A expressão "Sua queda é sua dignidade" - encontra-se na exposição da categoria Deus, da Lógica da filosofia de Eric Weil (WEIL, 2012a, p. 252)², no interior do momento inicial em que a categoria, apresentando-se em seu discurso próprio, tematiza a compreensão do homem, na atitude da fé, como criatura e como imagem. A fórmula - "Feliz culpa” - é extraída do Precônio Pascal, hino litúrgico conhecido como Exultet, cantado em exaltação ao Círio Pascal na celebração da Vigília da Páscoa cristã. A fórmula é, comumente, atribuída a Santo Agostinho. Mas o estudioso agostiniano Sébastien Antoni sustenta que "no imenso corpus oferecido por Santo Agostinho não se encontra (ainda) referência atestada”. Segundo o estudioso, se se aceita o testemunho do humanista e eclesiástico francês Guilherme Durando (1230-1296), a fórmula seria atribuível a Santo Ambrósio, dado que ela "corresponde a um pensamento que lhe é familiar", e que “o autor do Exultet se parece a Ambrósio como a um irmão” (ANTONI, 2013, p. 50).

A Agostinho se atribuiu, ao que parece, equivocadamente, além da fórmula "Feliz culpa", até mesmo a composição do Exultet3. É provável que

\footnotetext{
${ }^{1}$ Da vasta produção de Bernardo, destaco a sua tese doutoral, que se tornou referência nos estudos weilianos: Bernardo (2003).

${ }^{2}$ A exposição da categoria se desenvolve em cinco etapas, entre as páginas 249 a 286 da obra. A expressão se encontra na primeira etapa (WEIL, 2012a, p. 249-255), na qual, segundo a expressão de Bernardo, "a categoria é apresentada no seu discurso próprio" (BERNARDO, 2003a, p. 529).

${ }^{3}$ Sobre a composição do Exultet e sua pretensa atribuição a Santo Agostinho, Sébastien Antoni remete a Leclercq (1922, p. 15211574).
} 
esses equívocos se devam ao fato de a expressão pecado original ter sido criada por Agostinho. Com efeito, já no Ad Simplicianum, portanto, “quinze anos antes da polêmica anti-pelagiana", pecado original designa "aquele pecado que 'entrou no mundo' (Rm 5,12) pela falta de Adão e que afeta todo homem pelo fato mesmo de nascer" (SENTIS, 2004, p. 1370 s.).

Dado que não sou especialista em história dos dogmas ou em teologia dogmática, não tenho a pretensão de me pronunciar sobre questões da doutrina agostiniana do pecado original, que ainda hoje são objeto de debate na teologia4. Para os modestos objetivos da presente reflexão, considero legítimo lançar mão do auxílio de algumas 'autoridades' para uma brevíssima exposição da doutrina agostiniana do pecado original em vista de, posteriormente, aproximá-la da fórmula weiliana sobre a queda e a dignidade do homem.

\section{Agostinho, "inventor" do pecado original?}

Como observei acima, já no Ad Simplicianum Agostinho demonstra estar “em plena posse de sua doutrina” sobre o pecado original. Entretanto, para combater a doutrina de Pelágio sobre o livre-arbítrio, Agostinho desenvolveu certos aspectos polêmicos de sua doutrina, que repercutiram no concílio de Cartago (418), como a afirmação de que "a morte de Adão é a consequência de seu pecado, e que o pecado original nas criancinhas é um verdadeiro pecado”, e também no concílio de Orange (529), que afirma que "Adão transmitiu à sua descendência um verdadeiro pecado e uma servidão espiritual". Ora, "a influência de Agostinho sobre esses concílios e sobre o ensinamento oficial posterior da Igreja católica é inegável” (SENTIS, 2004, p. 1371).

Contudo, os teólogos Vitorino Grossi e Bernard Sesboüé sustentam que duas questões principais se põem com relação ao pecado original: “foi Agostinho quem inventou o pecado original ou somente a expressão? Que valor dogmático se deve dar à tradição agostiniana que se instituiu na Igreja sobre esse dogma? Esses dois aspectos se condicionam reciprocamente e dizem respeito ao conjunto da compreensão da doutrina cristã do pecado original tanto pela

\footnotetext{
${ }^{4}$ Para o estado da arte da teologia pós-conciliar sobre o pecado original, ver Maldamé (2013). Para o estado da arte numa perspectiva histórica, ver Kaufmann (2012, p. 146-154).
} 
inteligência das Escrituras, em particular de são Paulo, quanto das decisões dogmáticas da Igreja” (GROSSI; SESBOÜÉ, 2003, p. 134).

Baseados em minucioso estudo de Athanase Sage (1967, p. 211-248) sobre o nascimento do dogma do pecado original, Grossi e Sesboüé distinguem três etapas na compreensão evolutiva do pecado original em Agostinho:

\begin{abstract}
[...] de 387 a 397, ou seja, até a resposta A Simplício, Agostinho via nos descendentes de Adão a herança de uma pena, a morte corporal, mas não o pecado dos primeiros pais; de 397 a 411, além da morte corporal, ele inclui nessa herança a morte da alma, que se tornou culpada, uma vez que ela é ferida de morte pela concupiscência (libido), e porque é sede do pecado; enfim, em 412-413, a expressão pecado original (peccatum originis ou originale) do tratado Sobre a pena e a remissão dos pecados significa o caráter hereditário da pena e do pecado de Adão. Assim, a distinção feita no início da polêmica pelagiana entre pena e pecado na herança de Adão pecador teria sido ultrapassada para não significar mais que um todo único. (GROSSI; SESBOÜÉ, 2003, p. 137).5
\end{abstract}

Foi o acirramento da crise pelagiana, após a primeira condenação de Celéstio em 412, pelo concílio de Cartago, que levou Agostinho a formular uma concepção do pecado original como pecado hereditário e a relacioná-lo com o batismo, particularmente o das crianças. O advogado e asceta Celéstio, a partir de 390 tornou-se discípulo de Pelágio, porta-voz de suas ideias e até mesmo líder dos pelagianos. A condenação pelo concílio foi renovada em 417 pelo papa Inocêncio I, mas suspensa por seu sucessor Zósimo. Por força dos protestos dos bispos africanos e pelos distúrbios provocados pelos pelagianos, o papa Zósimo reviu a questão e, com a publicação da carta Tractoria, em 418, renovou a excomunhão de Pelágio e de Celéstio, que serão novamente condenados como heréticos pelo concílio de Éfeso, em 431 (VANNIER, 2004b, p. 1376-1378).

A controvertida interpretação do texto de $\mathrm{Rm}$ 5,12, lido na versão da Vetus Latina, está no centro da concepção agostiniana do pecado original. Na versão latina que Agostinho tinha diante dos olhos o texto diz: "Eis por que, assim como por um só homem o pecado entrou no mundo, e pelo pecado a morte, e assim [o pecado] atingiu todos os homens, no qual (in quo) todos

\footnotetext{
${ }^{5}$ Sobre a evolução da doutrina agostiniana, ver também Sage (1969, p. 75-112). Para uma análise de caráter estritamente filosófico da evolução do pensamento de Agostinho sobre esta questão, ver Novaes Filho (2009, p. 287-325).
} 
pecaram...”. Na maioria dos manuscritos do texto grego consta o termo "a morte", ausente no texto latino: "Eis por que, assim como por um só homem o pecado entrou no mundo, e pelo pecado, a morte, e assim a morte atingiu todos os homens: aliás (eph'ô) todos pecaram...”. Nas notas ao texto, na Tradução Ecumênica da Bíblia (TEB 1994, p. 2180), feita a partir dos originais gregos, explica-se que a expressão grega traduzida por aliás, foi compreendida em três sentidos: 1) como uma conjunção (porque, pelo fato de que, em virtude de que, visto que, sob a condição de que); 2) como um relativo, cujo antecedente seria Adão (por causa do qual, em razão do qual, no qual); 3) como um relativo cujo antecedente seria a morte (por causa da qual, em vista da qual).

O sentido mais defensável parece ser o primeiro, enquanto Agostinho considera que o antecedente do relativo é o termo "pecado" ou o próprio Adão. Segundo Grossi e Sesboüé, ele “entende, pois, 'o pecado de Adão no qual todos pecaram'. Ora, o grego não permite essa interpretação, porque o antecedente 'hamartia/pecado' é feminino, ao passo que 'thanatos/morte' é masculino”. Entretanto, a teologia de Agostinho não depende só desse argumento: "para ele é toda a Escritura que ensina a universalidade da redenção em Cristo e, portanto, também a do pecado" (GROSSI; SESBOÜÉ, 2003, p. 149). Como se pode concluir da leitura agostiniana do texto bíblico, o argumento fundamental de Agostinho é de inspiração soteriológica: é a partir da confissão da universalidade da salvação que se passa à afirmação de que todos são solidários no pecado ${ }^{6}$.

$\mathrm{Na}$ reflexão teológica posterior à crise pelagiana, Agostinho voltou em diversas ocasiões à questão da origem do pecado e ao pecado das origens, particularmente nos livros XII-XIV de $A$ cidade de Deus, no livro XII de $A$ Trindade, e no livro XI do Comentário literal ao Gênesis. O fundo da questão remete ao

\footnotetext{
${ }^{6}$ Segundo Sentis (2004, p. 1373), a solidariedade de todos no pecado significa duas coisas: "uma unidade do gênero humano mais antiga e mais fundamental que todas as suas divisões; e a extensão da salvação a todos os que a querem".
} 
mistério do "poder pecar", contrapartida do "poder não pecar": o homem é falível (pode "desfalecer") porque é um ser finito; essa finitude, todavia, não é o pecado. O pecado começa com a atitude que o homem toma a respeito de sua própria finitude. [...] Para Agostinho, o pecado do ser ainda totalmente inocente, o pecado "absoluto" em certo sentido, é ao mesmo tempo um ato de orgulho e um ato de avareza. Ele rejeita que o pecado original seja um pecado sexual. $\mathrm{O}$ orgulho e a avareza são considerados não somente em sua dimensão moral, mas segundo a contradição "ontológica" que constituem em relação ao ser e à vocação do homem. (GROSSI; SESBOÜÉ, 2003, p. $151)^{7}$.

Essa compreensão teológica do pecado das origens terá papel decisivo na antropologia subjacente à moral agostiniana ${ }^{8}$. Na peregrinação pelo mundo, depois do pecado, o homem conservou a vontade de felicidade, que Agostinho chama de liberum arbitrium, mas perdeu a vontade de bem (voluntas bene vivendi), que ele entende como libertas. Entretanto, o querer do liberum arbitrium carece de poder para o bem: seu poder é o poder voluntário de pecar. No estado de inocência, o homem era dotado de liberdade para o bem, vale dizer, podia não pecar, tinha também o poder de pecar e, de fato, pecou. Mas o poder pecar refere-se apenas ao liberum arbitrium, não à libertas, pois Deus é summa libertas e não pode pecar. Como criatura e imagem, pelo dom da redenção, o homem poderá recuperar a participação na condição divina na vida bem-aventurada, que consistirá de novo em não poder pecar. Na vida beata dos justos a vontade de felicidade voltará a coincidir com a vontade de bem (ÁLVAREZ TURIENZO, 1988, p. 345-373).

Uma compreensão filosófica extremamente sucinta, mas igualmente aguda do problema teológico que Agostinho pretendeu resolver com a doutrina do pecado original9, encontra-se na reflexão de Paul Ricoeur sobre a liberdade. Para Ricoeur, o drama do pecado de orgulho revela a passagem da metafísica da ação finita à metafísica do desejo de Deus.

\footnotetext{
${ }^{7}$ Segundo os autores, essa compreensão da doutrina agostiniana se inspira em Agaësse (1986).

${ }^{8}$ Sobre a antropologia agostiniana, ver também Vannier (2004a, p. 68-74) e Lima Vaz (1993, p. 63-67).

${ }^{9}$ Em última análise, dado que Agostinho "precisava evitar a ideia de uma maldade substancialmente inata ao ser humano, era-lhe impossível dizer que o ser humano enquanto tal era mau. Em vez disso ele ensinava então que o primeiro pecado cometido em plena liberdade pelo primeiro ser humano e ancestral de todo o gênero humano teria tido como consequência que todos os seus descendentes nasceriam com uma irresistível tendência ao pecado, que sem a intervenção da graça de Deus inevitavelmente produziria seus efeitos." (KAUFMANN, 2012, p. 150).
} 
Essa virada pode ser reconhecida em Santo Agostinho, para quem a vontade se revela em sua terrível grandeza, na experiência do mal e do pecado; a liberdade tem o poder de negar o ser, de "recusar" e de "faltar", de "fugir" de Deus, de se "voltar para" a criatura: esse poder formidável - esse "poder pecar" - é a marca do infinito sobre a liberdade. (RICOEUR, 1971, p. 984).

\section{Eric Weil, leitor de Agostinho}

Em uma obra tão volumosa e, ao mesmo tempo, tão econômica de referências e citações em notas de rodapé, como é a Lógica da filosofia de Eric Weilio, não deixa de surpreender o fato de encontrar nela uma referência literal a Santo Agostinho, citando no corpo do texto a famosa frase do De Trinitate (XIV, 7): in interiore homine habitat veritas (WEIL, 2012a, p. 266).

Indício de que Weil tenha sido leitor de Agostinho é o fato de se encontrarem em sua biblioteca pessoal, herdada pelo Instituto Eric Weil da Universidade de Lille (INSTITUT ERIC WEIL, 2011), as edições latinas das Confissões e de $A$ cidade de Deus, além de uma tradução francesa das Confissões ${ }^{11}$. Que Weil tivesse alguma familiaridade com o pensamento de Agostinho pode-se constatar em pelo menos três textos de sua vasta produção. O primeiro é uma grande resenha de vários livros, sob o título de Cristianismo e política, publicada na Revista Critique em 1953. Entre os livros resenhados está o de Étienne Gilson, Les metamorphoses de la Cité de Dieu, que fora publicado em 1952 (WEIL, 1971b, p. 45-79) ${ }^{12}$. O segundo texto é um artigo intitulado Religião e política, de 1955, publicado originalmente em inglês, no periódico Confluence: An International Forum, de Cambridge, MA (WEIL, 1993, p. 103114) ${ }^{13}$. O terceiro texto, escrito originalmente em alemão para o periódico Marxismus-Studien, foi publicado em 1962 com o título A secularização da ação e do pensamento político na época moderna (WEIL, 1971a, p. 22-44) ${ }^{14}$.

\footnotetext{
${ }^{10} \mathrm{Na}$ edição francesa revisada (Paris, Vrin, 1974), em formato grande (16×24,5cm) e 442 páginas, há apenas 91 notas de rodapé.

${ }^{11}$ As obras são, respectivamente, as seguintes: Sancti Aurelii Augustini (1909; 1918); S. Aureli Augustini (1934); Saint Augustin (1947).

${ }^{12}$ Além do livro de Étienne Gilson, Les métamorphoses de la Cité de Dieu, foram resenhados o de Lionel Curtis, Civitas Dei, o de Christopher Dawson, Understanding Europe, e o de Arnold J. Toynbee, Civilization on Trial. Para a tradução francesa dessa última, ver Toynbee (1951).

${ }^{13} \mathrm{O}$ artigo em inglês, Religion and politics, foi publicado em Confluence; ver Weil (1955). O mesmo texto foi publicado, em tradução francesa de L. Nguyen-Dinh, na série Le temps de la réflexion: ver Weil (1981).

${ }^{14} \mathrm{O}$ original em alemão, com o título Die Säkularisierung der Politik und des politischen Denkens in der Neuzeit, foi publicado em 1962: ver Weil (1962).
} 
Não é o caso de expor, mesmo resumidamente, o pensamento de Weil nesses textos. Para os fins desta reflexão, é suficiente destacar que Weil se interessa, particularmente, pelo pensamento político de Agostinho. No texto de 1953, Weil manifesta concordância com a tese de Gilson segundo a qual "santo Agostinho foi o primeiro a pensar o problema da fé em suas relações com a política”, embora ele "não tenha criado uma doutrina coerente das relações concretas da Igreja e do Estado" (WEIL, 1971b, p. 51, 52) ${ }^{15}$. No texto de 1955 , Weil remete ao De Civitate Dei no contexto da polêmica em torno da distinção, de origem no Novo Testamento, "entre as coisas que pertencem a Deus e as que pertencem a Cesar", a partir da qual, "aos olhos da Igreja, segundo santo Agostinho, o Estado era uma instituição necessária por causa da queda do homem" (WEIL, 1993, p. 109). No texto de 1962, o De Civitate Dei é novamente citado no contexto das relações entre cristianismo e política. Segundo Weil, o cristianismo não é mais hostil ao Estado do que outras religiões de salvação que o precederam. Porém, o cristianismo desvaloriza radicalmente o Estado e a política.

\begin{abstract}
Ninguém exprimiu isso mais claramente do que Santo Agostinho: o Estado tem (e é) um bem específico, mas esse bem, por real que seja, não é o verdadeiro, é um bem para os filhos de Cain, não para os descendentes de Abel. Ele é a ordem, e enquanto tal ele é bom, mas essa ordem só é necessária e boa porque e porquanto o homem é pecador, seu valor situa-se no nível do pecado, não da santificação do pecador. (WEIL, 1971a, p. 41 s.) ${ }^{16}$.
\end{abstract}

Os indícios e os textos acima citados confirmam que Weil, efetivamente, leu Santo Agostinho, o que permite também falar de uma presença de Santo Agostinho na Lógica da filosofia, como sustenta a aguda reflexão de Luís Manuel Bernardo. Com efeito, o estudioso lusitano entende que

[a] referência algo intempestiva a S. Agostinho [...] constitui um reconhecimento da dívida do autor em relação a uma filosofia que lhe deu acesso a um discurso no interior do qual tem algumas dificuldades de orientação, resultantes, eventualmente, de se encontrar, segundo o próprio, "por mais do que uma razão, fora de qualquer cristianismo dogmático". (BERNARDO, 2003a, p. 528)17.

\footnotetext{
${ }^{15}$ Sobre as incoerências da doutrina agostiniana das relações Igreja-Estado, Weil (1971b, p. 52) afirma que Gilson (1949, p. 237, nota 2) tratou disso "magistralmente em uma nota de sua Introduction à l'étude de saint Augustin".

${ }^{16}$ As passagens do De Civitate Dei que, segundo Weil, exemplificam isso são: XV, 1 e XVI, 10.

${ }^{17}$ A afirmação de encontrar-se, "por mais de uma razão, fora de qualquer cristianismo dogmático", citada por Bernardo como eventual fonte de dificuldades de Weil com relação à filosofia de Agostinho, encontra-se no texto Christianisme et politique (WEIL, 1971b, p. 63).
} 
Tomando como guia a hipótese de que "o essencial da categoria e o essencial do discurso agostiniano possam coincidir" e, portanto, que "a construção da categoria de Deus está sustentada na leitura weiliana de S. Agostinho" (BERNARDO, 2003a, p. 529 e 530), não vou retomar o desenvolvimento extremamente bem articulado da hipótese, mas mantê-la diante de mim na exposição do que me interessa na categoria Deus da Lógica da filosofia, para aproximá-la, posteriormente, da doutrina agostiniana do pecado original ${ }^{18}$.

\section{Deus e a fé na Lógica da filosofia}

A Lógica da filosofia de Eric Weil é um sistema de filosofia que expõe de maneira coerente e exaustiva a pluralidade dos discursos filosóficos efetivamente realizados na história, nos quais o ser humano compreendeu a realidade e se compreendeu nas suas realizações (KIRSCHER, Paris, 1989). Esses discursos fundamentais ou puros são chamados categorias, que não devem ser entendidas como categorias do ser, como se costuma entendê-las a partir de Aristóteles, mas como categorias da filosofia, ou seja, como os discursos coerentes nos quais o ser humano compreendeu as suas atitudes e se compreendeu nas suas atitudes. A exposição sistemática dessas categorias se faz segundo a ordem das atitudes puras ou irredutíveis, que são os modos fundamentais de estar no mundo, pelos quais a realidade é apreendida e transformada. Uma atitude compreendida é uma categoria constitutiva de um discurso coerente na história (CAILLOIS, 1953, p. 273-291).

A sucessão das categorias na Lógica da filosofia não obedece a uma ordem histórica, mas lógica. Isso significa que elas se sucedem segundo a ordem das afirmações dos conteúdos de sentido pela liberdade que, ao negar uma atitude que não mais a satisfaz, produz uma nova atitude e, com ela, a possibilidade de um novo discurso no qual a realidade é compreendida. A

\footnotetext{
${ }^{18}$ Segundo Bernardo (2003a, p. 529), “o discurso agostiniano cumpriria, assim uma dupla exigência, a da tomada de consciência do que estava implicado na atitude do crente e o da constituição de uma espécie de transparência para a dialéctica da discursividade total, patenteando, ou permitindo patentear, os conceitos de esteio da filosofia, dicção mediadora enquanto acesso em direção à origem, ao tal discurso anterior ao da teologia e das religiões, mas apropriado à compreensão da atitude, e ancoragem na discursividade filosófica, garantindo a compreensão da categoria pela filosofia".
} 
ordem da sucessão das categorias não é, portanto, a ordem imanente do autodesenvolvimento da razão, mas a das invenções da liberdade que, ao recusar um conteúdo antigo, tornado antigo justamente por essa recusa, dá a si mesma um novo conteúdo ${ }^{19}$.

No interior da realidade, o ser humano se encontra sempre numa determinada atitude, que é a sua própria vida, tal como ele a sente. A atitude é o sentido do seu mundo material e espiritual, dos valores que habitam as coisas e orientam seus atos e sentimentos, ela é o modo de ser e de viver como humanamente no mundo. Em princípio o ser humano não é consciente de sua atitude, pois ele simplesmente a vive. A atitude normalmente não se pensa, porém, é nela que o ser humano pensa e age no seu mundo.

Como ser discursivo-agente, o ser humano exprime seu mundo vivido de maneira coerente, embora essa coerência seja parcial. Porém, quando traduz coerentemente sua atitude, ele se distancia dela, não se confunde mais com ela, mas a domina e a fixa. Feito isso, ele pode até rejeitar a atitude na qual se mantinha, dado que pelo discurso inaugurou uma nova atitude. Como agente discursivo, o ser humano pode transformar toda atitude em discurso e produzir uma categoria, isto é, um conceito organizador de um discurso coerente. A categoria exprime no plano do discurso a coerência parcial da atitude compreendida.

As primeiras 16 categorias da Lógica traduzem discursivamente o conjunto das atitudes puras ou fundamentais do ser humano. A primeira série de sete categorias (Verdade, Não-senso, Verdadeiro-e-falso, Certeza, Discussão, Objeto e Eu), reúne as que Weil chama de categorias antigas; a segunda série de oito categorias (Condição, Consciência, Inteligência, Personalidade, Absoluto, Obra e Ação) reúne as chamadas categorias modernas. A modo de gonzo entre essas duas séries encontra-se a categoria Deus. As duas últimas categorias (Sentido e Sabedoria) são categorias formais e constituem a pedra angular de todo o sistema.

\footnotetext{
${ }^{19}$ Sobre a ideia de uma lógica da filosofia, remeto a Perine (2013, p. 142-152).
} 
Deus entra no discurso filosófico porque a fé é uma das atitudes puras do ser humano no mundo ${ }^{20}$. Na tradição ocidental de filosofia, a atitude em questão é a que foi introduzida no mundo pela fé bíblica, que remete a um substrato comum ao judaísmo, ao cristianismo e ao islã. A Lógica da filosofia pretende captar a atitude da fé na sua pureza. Para isso é preciso partir do fato de que a fé é vivida pelo crente como sentimento religioso em estado puro, aquém da sua sistematização sob a forma de teologia. A fé como atitude se apresenta como o móvel da intencionalidade religiosa cujo termo - Deus ou o Divino - responde ao sentimento que projeta o ser humano em direção ao contentamento (eudaimonia ou beatitude). A fé é uma das atitudes humanas puras porque nela o ser humano não se descobre apenas como razão oposta à natureza, mas também como sentimento.

A atitude da fé se revela como sentimento (que não se confunde com sentimentalismo), que pertence ao imediatamente vivido. No âmbito do imediatamente vivido, o ser humano se experimenta como coração, que só deseja ser feliz. Mas o coração pode ser bom ou mau. Essa dualidade irrecusável está na raiz do sentimento de separação e de responsabilidade que o crente experimenta na atitude da fé. Na linguagem da fé o sentimento de separação se traduz como queda; o de responsabilidade se traduz como liberdade, não no sentido jurídico, mas como o fundo da sua existência: no seu coração o crente se descobre como liberdade que pode se determinar pelo bem e pelo mal, como liberdade que se determinou, e se determinou mal, pois do contrário não se encontraria como ser determinado.

Nessa atitude, portanto, o crente se descobre como liberdade determinada. Mas sua liberdade e seu ser para si só se realizam ao preço da separação que ele experimenta com relação à sua origem. Se ele não sentisse em si a dualidade do bem e do mal, se não se experimentasse como ser decaído, não teria nada de próprio. É só na tentação e na queda que a liberdade se apreende como liberdade capaz de captar o bem e o mal. O crente, assim, se compreende como liberdade separada de sua fonte, como liberdade originada, derivada e

\footnotetext{
${ }^{20} \mathrm{Na}$ impossibilidade de "resumir" o desenvolvimento do discurso weiliano, a exposição que se segue pretende "traduzir" a exposição da categoria Deus na Lógica da filosofia (WEIL, 2012a, p. 248-263). Desenvolvi amplamente essa questão em outro lugar: Perine (1993, p. 477-497).
} 
decaída. Ele seria um ser puramente natural, um animal cuja inteligência técnica seria apenas mais hábil que a dos outros animais, se não tivesse uma regra para distinguir o bem do mal. Essa regra lhe é dada pela sua própria fonte, que vem em seu socorro.

Na atitude da fé o crente se compreende em Deus e só a partir dessa compreensão pode ser feliz, pois seu sentimento de si é o sentimento de sua separação de Deus e de sua existência derivada de Deus. Em linguagem bíblica, na atitude da fé o ser humano se descobre como criatura e imagem do Deus transcendente e inacessível, que, contudo, lhe fala ao coração, revelando-se como fonte e fim de sua existência. Pela revelação o crente aprende o que é Deus e, por Deus, aprende o que ele próprio é: criatura e imagem. Pela revelação aprende a distinguir o bem do mal e, assim, de simples imagem de Deus, tornase semelhante a Deus. Para ser a imagem viva de Deus, isto é, para ser livre, ele deve ouvir a lei de Deus e desobedecê-la, dado que é na lei divina e no ato de desobediência que ele se descobre a si mesmo como ser separado e responsável pelos seus atos: "sua queda é sua dignidade" (WEIL, 2012a, p. 252).

Nessa atitude pode-se reconhecer facilmente a concepção das relações entre o ser humano e Deus formulada nos primeiros capítulos do livro do Gênesis. As grandes linhas da atitude da fé como atitude irredutível do ser humano que se compreende como sentimento, permite ver em que consiste a categoria Deus na Lógica da filosofia. Ela consiste nisso: o ser humano se compreende em Deus (BOUILLARD, 1977, p. 543-621). O que se reconhece aqui é a ideia bíblica de Deus - transcendente, onipotente, criador - e a ideia bíblica do homem - criatura livre, imagem e semelhança de Deus. Na verdade, Deus é o único Eu, e o homem só é um eu por derivação. A razão e o sentimento humanos só são essencialmente sentimento e razão sob a condição de se conformarem à razão e ao sentimento divino. Porém, completamente unido a Deus o ser humano não seria mais um Eu: seu ser para si, isto é, sua liberdade só se realiza existencialmente ao preço da separação. Separado de Deus pelo mesmo laço que o une a Ele, o ser humano é, ao mesmo tempo, si mesmo e outro de si mesmo. (KIRSCHER, 1989, p. 260). 
Para a Lógica da filosofia o que está em questão não é a existência ou a não-existência de Deus, "mas a relação do homem e de Deus enquanto figura do sentido, dito de outro modo, enquanto figura da relação da liberdade à razão” (KIRSCHER, 1989, p. 263). Para o crente, que vive na atitude da fé, o fato de sua essência ser Deus e sua existência ser a queda do estado divino significam que sua contradição é apenas existencial, não essencial, e que ela desaparecerá com o retorno a Deus. Portanto, para a atitude pura do crente, "o que o homem é se revela em Deus; Deus não é antropomorfo, exceto para a linguagem do mundo e da necessidade: o homem é teomorfo" (WEIL, 2012a, p. 272).

\section{Conclusão: queda e dignidade, culpa e felicidade}

Antes de concluir, retomo o ponto de partida da presente reflexão, isto é, a hipótese interpretativa de Luís Manuel Bernardo sobre a presença de Santo Agostinho na Lógica da filosofia de Eric Weil. Segundo esse agudo leitor da obra weiliana,

[à] concepção agostiniana corresponde, para Weil, uma dupla função dialética: por um lado, ela parece constituirse como a fonte matricial da atitude do crente e do discurso categorial que permite a sua dicção; por outro lado, o que ela deu a ver ao filósofo da lógica foi o princípio do movimento de superação da categoria, o que para o efeito é o mesmo, a compreensão do seu papel na lógica da filosofia. (BERNARDO, 2003a, p. 528).

Entretanto, meu interesse pelo "paradoxo de uma presença/ausência de S. Agostinho na Logique de la Philosophie de Eric Weil" (BERNARDO, 2003a, p. 535), situou-se na linha de uma aproximação entre a concepção teológica do pecado original como "feliz culpa", atribuída a Agostinho, e a tematização weiliana da atitude da fé, na categoria Deus da Lógica da filosofia, na qual se explicita a concepção filosófica da queda como dignidade do ser razoável "finito e livre" ${ }^{21}$. Meu interesse, portanto, era de fundo antropológico porque, a meu ver, o discurso categorial que permitiu a diç̧ão da atitude do crente revela, a contraluz, as linhas fundamentais da concepção antropológica do lógico da

\footnotetext{
${ }^{21}$ A fórmula "ser razoável finito e livre" como chave de compreensão da antropologia de Weil é, evidentemente, de extração kantiana. Sobre isso, ver Weil (2012b).
} 
filosofia, que, nas categorias subsequentes da Lógica, particularmente nas da Consciência e da Ação, às quais correspondem, respectivamente, a sua Filosofia moral (WEIL, 2011a) e a sua Filosofia política (WEIL, 2011b), vai operar o princípio do movimento de superação da categoria Deus e, portanto, evidenciar o seu papel na lógica da filosofia. Com efeito, Weil afirma que a categoria Deus é

[o] ponto de virada do devir filosófico, a mais moderna das categorias antigas, a mais antiga das modernas. Nela, trata-se da compreensão do homem; para nós, o homem aí é tudo, mas justamente nessa atitude o homem não é nada (porque, para ele próprio, ele é apenas reflexo). (WEIL, 2012a, p. 268).

A compreensão agostiniana do pecado das origens, como foi dito acima, teve papel decisivo na antropologia de Santo Agostinho. Segundo Lima Vaz, três fontes confluíram na visão agostiniana do ser humano. A primeira, o neoplatonismo, base da sua formação filosófica, o influenciará "sobretudo na elaboração da estrutura do 'homem interior' coroada pela mens (equivalente ao nous da antropologia neoplatônica) e na qual Deus está presente como interior e superior (interior intimo et superior summo, Conf. III, 6)". A segunda, a antropologia paulina, cuja visão do homem é eminentemente soteriológica, a partir da qual Agostinho "formulará a doutrina do pecado original e da graça e aprofundará, no contexto da controvérsia pelagiana, o problema da liberdade e do livre-arbítrio [...] que se tornará [...] uma matriz fundamental para a elaboração da ideia do homem característica da nossa civilização”. Finalmente, a antropologia da narração bíblica da criação, da qual emerge "o tema fundamental da antropologia patrística sobre o homem imagem de Deus que Agostinho trata com predileção e do qual a sua antropologia recebe o paradigma ideal para julgar a verdadeira natureza e a destinação do homem (ver Conf., XIII, 22-24)” (LIMA VAZ, 1993, p. 64 s.)22.

Como se viu acima, a categoria Deus na Lógica da filosofia consiste em que o ser humano se compreende em Deus. Isso significa, para a atitude pura do crente, que Deus não é antropomorfo, mas o homem é teomorfo. Esse "resultado" da categoria Deus na Lógica da filosofia parece indicar,

\footnotetext{
${ }^{22}$ Ver também: A metafísica da interioridade em Santo Agostinho, em Lima Vaz (2001, p. 77-87).
} 
suficientemente, que, em chave antropológica, a leitura de Agostinho teria aberto para Eric Weil, como sustenta Luís Bernardo, o "acesso a um discurso no interior do qual [Weil] tem algumas dificuldades de orientação, resultantes, eventualmente, de se encontrar, segundo o próprio, 'por mais do que uma razão, fora de qualquer cristianismo dogmático”" (BERNARDO, 2003a, p. 528).

Foi a antropologia agostiniana, na qual confluíram, segundo Lima Vaz, o neoplatonismo, com a ideia de homem interior; a antropologia paulina, de caráter soteriológico, e a antropologia da narração bíblica da criação, cujo centro é a afirmação do homem como imagem de Deus, que ofereceu ao lógico da filosofia o discurso adequado à tematização da atitude da fé na categoria Deus como ponto de virada do discurso filosófico, no qual, pela primeira vez, o homem se encontra no centro. Entretanto, a tematização das linhas fundamentais da antropologia do lógico da filosofia e sua concepção do ser humano como finito e livre se dará na categoria da consciência (WEIL, 2012a, p. 329-369), e em seu desdobramento na obra Filosofia moral (WEIL, 2011a).

Se uma interpretação do conjunto da obra weiliana em chave de um kantismo pós-hegeliano, como pretendi ter feito em minha tese de doutoramento (PERINE, 2013); se a fórmula, de extração kantiana, que define o ser humano como razoável "finito e livre" pode ser tomada como eixo da concepção antropológica weiliana ${ }^{23}$; se, por fim, para retomar a afirmação de Paul Ricoeur, o drama do pecado original revela a passagem da metafísica da ação finita à metafísica do desejo de Deus, passagem que se deve a Agostinho, para quem a vontade se mostra grande na experiência do mal e do pecado, e o 'poder pecar' se torna a marca do infinito sobre a liberdade, penso ser perfeitamente adequado encerrar esse pequeno artigo com uma citação do capítulo "O mal radical, a religião e a moral”, dos Problemas kantianos de Eric Weil:

Kant, ao que saibamos, não utiliza a expressão felix culpa. Ele poderia tê-lo feito, pois é a queda que leva à salvação um ser que, sem ela, apenas vegetaria; a história - história moral e história simplesmente começa pelo mal, pois o bem não tem história. (WEIL, 2012b, p. 162).

\footnotetext{
${ }^{23}$ Sobre o kantismo de Eric Weil, ver também Canivez (2014, p. 9-28).
} 


\section{REFERÊNCIAS}

AGAËSSE, Paul. L'anthropologie chrétienne selon saint Augustin: image, liberté, péché et grâce. Paris: Centre Sèvres, 1986.

ÁLVAREZ TURIENZO, Saturnino. La Edad Media. I. Moral de San Agustín. In: CAMPS, Victoria (ed.). Historia de la ética: de los griegos al Renacimiento. Barcelona: Editorial Crítica, 1988. v. 1. p. 345-373.

ANTONI, Sébastien. O Felix Culpa. Itinéraires Augustiniens, v. 50, p. 50-52, juil. 2013. Disponível em: https://www.assomption.org/fr/mediatheque/revue-itinerairesaugustiniens/itineraires-augustiniens-50-tout-est-grace-juillet-2013-1/felix-culpa. Acesso em: 10 maio 2019.

BERNARDO, Luís Manuel A. V. Linguagem e discurso: uma hipótese hermenêutica sobre a filosofia de Eric Weil. Lisboa: Imprensa Nacional-Casa da Moeda, 2003.

BERNARDO, Luís Manuel A. V. Presença de Santo Agostinho na Logique de la Philosophie de Eric Weil. In: Actas do Congresso Internacional «As Confissões de Santo Agostinho, 1600 anos depois: presença e actualidade». Lisboa: Universidade Católica Editora, 2003a. p. 523-535.

BOUILLARD, Henri. Philosophie et religion dans l'oeuvre d'Éric Weil. Archives de Philosophie, Paris, v. 40, p. 543-621, 1977.

CAILLOIS, Roger. Attitudes et catégories. Revue de Métaphysique et de Morale, Paris, n. 58, p. 273-291, 1953.

CANIVEZ, Patrice. O kantismo de Eric Weil. Argumentos, ano 6, n. 11, p. 9-28, jan.jun. 2014.

GILSON, Etienne. Introduction à l'étude de saint Augustin. 3. ed. Paris: Vrin, 1949.

GROSSI, Vitorino; SESBOÜÉ, Bernard. Pecado original e pecado das origens: de santo Agostinho ao fim da Idade Média. In: SESBOÜÉ, Bernard (org.). História dos dogmas: o homem e sua salvação (séculos V - XVII). Tradução de Orlando Soares Moreira. São Paulo: Edições Loyola, 2003. v. 2. p. 133-162.

INSTITUT ERIC WEIL. 9 déc. 2011. Disponível em: https://eric-weil-recherche.univlille3.fr/. Acesso em: 04 jun. 2019.

KAUFMANN, Thomas (org.). História ecumênica da Igreja: dos primórdios até a Idade Média. Tradução de Irineu J. Rabuske. São Paulo: Edições Loyola: Paulus; São Leopoldo: Editora Sinodal, 2012. v. 1. p. 146-154.

KIRSCHER, Gilbert. La philosophie d'Eric Weil: systématicité et ouverture. Paris: PUF, 1989. 
LECLERCQ, Henri. Pâques. In: CABROL, Fernand; LECLERCQ, Henri (dir.). Dictionnaire d'archéologie chrétienne et de liturgie. Paris: Librairie Letouzey et Ané, 1922. v. 13.p. 1521-1574. Disponível em:

https://gallica.bnf.fr/ark:/12148/bpt6k34123919/f18.item. Acesso em: 29 maio 2019.

LIMA VAZ, Henrique Claudio de. Antropologia filosófica I. 3. ed. rev. São Paulo: Edições Loyola, 1993.

LIMA VAZ, Henrique Claudio de. Escritos de Filosofia VI: ontologia e história. São Paulo: Edições Loyola, 2001.

MALDAMÉ, J.-M. O pecado original: fé cristã, mito e metafísica. São Paulo: Edições Loyola, 2013.

NOVAES FILHO, Moacyr Ayres, A razão em exercício: estudos sobre a filosofia de Agostinho. 2. ed. São Paulo: Discurso Editorial/Editora Paulus, 2009.

PERINE, Marcelo. Deus no discurso filosófico. Síntese Nova Fase, v. 20, n. 6o, p. 477-497, 1993.

PERINE, Marcelo. Filosofia e violência: sentido e intenção da filosofia de Eric Weil. 2. ed. rev. São Paulo: Edições Loyola, 2013.

RICOEUR, Paul. Liberté. In: ENCYCLOPAEDIA UNIVERSALIS FRANCE. Paris: 1971. V. 9. p. 979-985.

S. AURELI AUGUSTINI. Confessionum libri tredecim: post Pium Knoell; iteratis curis edidit Martinus Skutella. Lipsiae: B. G. Teubneri, 1934.

SAGE, Athanase. Le péché originel dans la pensée de saint Augustin, de 412 à 430.

Revue d'Études Augustiniennes et Patristiques, Turnhout, v. 15, n. 1-2, p. 75112, 1969. Disponível em:

https://www.brepolsonline.net/doi/abs/10.1484/J.REA.5.104166. Acesso em: 4 jun. 2019.

SAGE, Athanase. Péché originel. Naissance d'un dogme. Revue d'Études

Augustiniennes et Patristiques, Turnhout, v. 13, n. 3-4, p. 211-248, 1967. Disponível em: https://www.brepolsonline.net/doi/pdf/10.1484/J.REA.5.104140. Acesso em: 4 jun. 2019.

SAINT AUGUSTIN. Confessions. Traduction de Louis de Mondadon. Paris: Éditions de Flore, 1947.

SANCTI AURELII AUGUSTINI, episcopi. De civitate Dei: libri XXII. Lipsiae: Bernhard Dombart, 1909. v. 1, lib. I-XII. (B. G. Teubneri).

SANCTI AURELII AUGUSTINI, episcopi. De civitate Dei: libri XXII. Lipsiae: Bernhard Dombart, 1918. v. 2, lib. XIV-XXII. (B. G. Teubneri).

SENTIS, Laurent. Pecado original. Dicionário crítico de teologia. Sob a direção de Jean-Yves Lacoste. Tradução de Paulo Meneses et al. São Paulo: Paulinas: Edições Loyola; 2004. p. 1370-1374. 
TOYNBEE, Arnold J. La civilisation à l'épreuve. Paris: Éditions Gallimard, 1951.

TRADUÇÃO ECUMÊNICA DA BÍBLIA (TEB). Coord. editorial: Johan Konings. São Paulo: Edições Loyola, 1994.

VANNIER, Marie-Anne. Agostinho de Hipona. Dicionário crítico de teologia. Sob a direção de Jean-Yves Lacoste. Tradução de Paulo Meneses et al. São Paulo: Paulinas: Edições Loyola, 2004a. p. 68-74.

VANNIER, Marie-Anne. Pelagianismo. Dicionário crítico de teologia. Sob a direção de Jean-Yves Lacoste. Tradução de Paulo Meneses et al. São Paulo: Paulinas: Edições Loyola, 2004b. p. 1376-1378.

WEIL, Eric. Christianisme et politique. In: WEIL, Eric. Essais et conférences. Paris: Plon, 1971b. v. 2. p. 45-79.

WEIL, Eric. Die Säkularisierung der Politik und des politischen Denkens in der Neuzeit. Marxismusstudien, Tübingen, v. 4, p. 144-162, 1962.

WEIL, Eric. Filosofia moral. Tradução de Marcelo Perine. São Paulo: É Realizações, 2011a.

WEIL, Eric. Filosofia política. Tradução de Perine. 2. ed. São Paulo: Edições Loyola, 2011b.

WEIL, Eric. La sécularisation de l'action et de la pensée politiques à l'époque moderne. Paris: Plon, 1971a. p. 22-44. (Essais et conférences, II).

WEIL, Eric. Lógica da filosofia. Tradução de Lara Christina de Malimpensa. São Paulo: É Realizações, 2012a.

WEIL, Eric. Problemas kantianos. Tradução de Luiz Paulo Rouanet. São Paulo: É Realizações, 2012b.

WEIL, Eric. Religion and politics. Confluence, v. 4, n. 2, p. 202-214, 1955.

WEIL, Eric. Religion et politique. Essais sur la philosophie, la démocratie et l'éducation. In: WEIL, Eric. Essais et conférences. Lille: Presses Universitaires de Lille, 1993. p. $103-114$.

WEIL, Éric. Religion et politique. Le temps de la réflexion, Paris, n. 2, p. 183-195, 1981. 